\title{
How to Manage Synchronous Endometrial and Ovarian Cancer Patients?
}

\author{
Wonkyo Shin \\ NCC: National Cancer Center \\ Sang-yoon Park \\ NCC: National Cancer Center \\ Sokbom Kang \\ NCC: National Cancer Center \\ Myongcheol Lim \\ NCC: National Cancer Center \\ Sang-Soo Seo ( $\sim$ ssseomd@ncc.re.kr) \\ National cancer center https://orcid.org/0000-0003-2381-0965
}

\section{Research}

Keywords: endometrial neoplasms, synchronous cancer, ovarian cancer, metastasis, prognosis

Posted Date: December 11th, 2020

DOI: https://doi.org/10.21203/rs.3.rs-125236/v1

License: (c) (i) This work is licensed under a Creative Commons Attribution 4.0 International License. Read Full License 


\section{Abstract}

Purpose: We aimed to evaluate the prognosis in patients with synchronous endometrial and ovarian cancer (SEOC) by comparing the differences between double primary cancer (DPC) and metastatic cancer (MC).

Methods: The medical records of 47 patients diagnosed synchronously with endometrial and ovarian cancer between January 2006 and December 2018 were retrospectively reviewed. Twenty-eight and 19 patients were diagnosed with DPC and MC, respectively. Demographics, recurrence-free survival (RFS), and 5year overall survival (OS) were compared. The clinical factors affecting survival were evaluated using univariate and multivariate analyses.

Results: The demographics were not different between both groups. Endometrioid histology and the International Federation of Gynecology and Obstetrics grade were higher in the MC group than in the DPC group (42.1\% vs. $10.7 \%$; $=0.018, P=0.002$, respectively). The ratio of post-operative adjuvant therapy was not different in both groups. Recurrence occurred in five patients with DPC and seven with MC. The difference in RFS was not significantly different ( $P=0.131)$ but the OS was different between both groups $(P=0.020)$. Histology and para-aortic lymph node metastasis were associated wtih RFS in univariate analysis, but no difference was found in multivariate analysis.

Conclusions: Although DPC patients had longer OS, multivariate analysis did not identify any influential factors. Focus should be placed on defining the appropriate adjuvant treatment for high-risk patients, which will improve prognosis, rather than on discriminating between DPC and MC.

\section{Introduction}

Endometrial cancer has the highest incidence among gynecological cancers in Western countries [1]. In Korea, the diagnosis of endometrial cancer has been steadily increasing over the last 10 years [2]. Endometrial cancer is usually diagnosed at an early stage because patients present for consultations at the hospital with abnormal vaginal bleeding or discharge. The diagnosis is usually confirmed either by biopsy with endometrial curettage or hysteroscopy. The disease status is confirmed through imaging (computed tomography [CT] scan or magnetic resonance imaging [MRI]), and then the treatment method is determined. If the tumor is resectable, a surgery involving total hysterectomy, bilateral salpingo-oophorectomy, pelvic and para-aortic lymph node (LN) dissection is performed. The adjuvant treatment option is chosen based on the pathologic report. Cancer may also be found incidentally in the ovaries in about $7 \%$ of the endometrial cancer patients [3]. The tumor stages in such cases are dependent on whether it is a metastasis of an endometrial cancer, metastasis of an ovarian cancer, or a co-occurrence of both cancers in the ovaries and endometrium.

In 1985, Ulbright and Roth proposed criteria for distinguishing metastatic cancer (MC) from double primary cancer (DPC) in such cases. In 1998, Scully proposed more detailed diagnostic criteria. Since the above criteria are widely used, there are many studies comparing the characteristics and prognoses in these two groups (MC and DPC) [4-15]. A prior study suggested that the prognosis was poor when metastasis involved other sites in addition to the uterus and ovaries and when there was no distinction between the DPC and MC [5]. Endometrioid histology has been shown to have a better prognosis than nonendometrioid histology [6, 7]. Compared to DPC, MC has a poorer prognosis with cervical invasion, a large tumor size, and high-grade histology [8]. Early-stage DPC showed a good prognosis in a study conducted only on DPC patients [10]. Song et al. showed the association of the initial CA-125 level and ovarian stage with DPC survival [11], while Jain et al. showed the association between lymphovascular invasion and DPC survival [12]. When comparing DPC with endometrial cancer, prognosis is not inferior than that in endometrial cancer [13]. However, the prognosis in patients with cervical invasion, LN metastasis, and peritoneal dissemination, regardless of DPC or MC, is poor [15]. Overall, the prognosis is good in early-stage DPC. It is difficult to accurately differentiate between DPC and MC based on these classical criteria or morphological differences including histopathology, size, and spread to adjacent organs.

On the one hand, in 2016, two independent studies reported that most synchronous endometrial and ovarian cancers (SEOCs) were single primary tumors with metastases; this was evaluated using massively parallel sequencing $[16,17]$. Accordingly, Chao et al. analyzed 16 SEOC patients with massively parallel sequencing and copy number analysis [18]. These studies support the fact that SEOC is a metastatic disease and not a DPC. However, it is difficult to apply these results in real-world clinical settings, because of high cost and long time needed for analysis.

On the other hand, categorization of the tumor as either DPC or MC is important for accurate diagnosis. However, determining the appropriate treatment modality for patients diagnosed with either DPC or MC is more important. If the diagnosis is DPC, each organ's tumor is staged as IA; if the diagnosis is MC, the tumor is staged as IIIA based on the endometrial cancer staging or IIA based on the ovaries. It is thus important to know if the cancer occurs synchronously in the ovaries and endometrium or metastasizes from one organ to another. This helps to select patients who need adjuvant treatment, be it in the form of chemotherapy or radiotherapy. Therefore, we analyzed and compared the baseline characteristics of DPC and MC patients and analyzed the risk factors for recurrence.

\section{Material And Methods}

\section{Study population}

The electronic medical records of patients who were newly diagnosed with endometrial cancer and ovarian cancer at the National Cancer Center in South Korea between January 2006 and December 2018 were reviewed. Forty-seven patients who had been diagnosed and treated at our center were included in the analysis. Patient clinical characteristics, including age at diagnosis, tumor size, radicality of hysterectomy, LN dissection, lymphovascular invasion, endocervical invasion, International Federation of Gynecology and Obstetrics (FIGO) stage and grade, histology, surgical procedure, and the records of postoperative adjuvant chemotherapy and radiotherapy, were collected through an electronic search of the center's medical records.

2. Statistical analysis

Page $2 / 10$ 
Correlations of variables were assessed using Fisher's exact test or Student's t-test. The five-year overall survival (OS) and recurrence-free survival (RFS) were estimated using the Kaplan-Meier method, and the significance of differences was determined using log-rank tests. Univariate and multivariate Cox regression analyses were performed to identify the patient characteristics associated with prognosis. Hazard ratios (HR) were calculated. P-values $<0.05$ were considered significant.

\section{Results}

Among the total of 47 patients, 28 were diagnosed with DPC, and 19 with MC. The demographics of the two groups are compared in Table 1. Surgical approach, LN dissection, lymph node pathology, lymphovascular invasion, and endocervical invasion were not different between the two groups. The endometrial cancer and ovarian cancer FIGO grades were significantly higher in the MC group than in the DPC group $(P=0.001, P=0.026$, respectively). Endometrioid histology of the endometrium was higher in the DPC group $(P=0.018)$. Post-operative adjuvant therapy in the two groups was not different. The Kaplan-Meier survival analyses of RFS and 5-year OS are shown in Fig. 1. Differences in RFS were not statistically different $(P=0.131)$, but the difference in OS was significant $(P=0.020)$. In univariate analysis, endometrioid histology of the endometrium $(P=0.002)$ and ovary $(P=0.016)$ showed lower recurrence than other histologies, and para-aortic lymph node metastasis was related to recurrence $(P=0.026)$. Lymphovascular invasion, endocervical invasion, and FIGO grade were not related to recurrence. No clinical factors were found in multivariate analysis. Only endometrioid histology compared with nonendometrioid histology showed a trend to better OS ( $\mathrm{HR}=0.09, \mathrm{P}=0.035)($ Table 2$)$. Twelve patients $(5 \mathrm{DPC}$ and $7 \mathrm{MC})$ showed disease recurrence. The detailed clinical characteristics of recurrent patients are descripted in Table 3. There were no specific different clinical factors, four patients are died in MC group, but no patients died in DPC. 
Table 1

Baseline characteristics of patients

\begin{tabular}{|c|c|c|c|c|}
\hline Variables & Total $(\mathrm{N}=47)$ & $\mathrm{DP}(\mathrm{N}=28)$ & meta $(N=19)$ & P-value \\
\hline Age (med, min-max) & $52(24-70)$ & $50(24-69)$ & $54(39-70)$ & 0.263 \\
\hline Approach & & & & 1.000 \\
\hline Laparoscopy & $9(19.1)$ & $5(17.9)$ & $4(21.1)$ & \\
\hline Laparotomy & $38(80.9)$ & $23(82.1)$ & $15(78.9)$ & \\
\hline PLND & & & & 0.685 \\
\hline No & $7(14.9)$ & $5(17.9)$ & $2(10.5)$ & \\
\hline Yes & $40(85.1)$ & $23(82.1)$ & $17(89.5)$ & \\
\hline PALND & & & & 1.000 \\
\hline No & $12(25.5)$ & $7(25.0)$ & $5(26.3)$ & \\
\hline Yes & $35(74.5)$ & $21(75.0)$ & $14(73.7)$ & \\
\hline LVS I & & & & 0.417 \\
\hline No & $40(85.1)$ & $25(89.3)$ & $15(78.9)$ & \\
\hline Yes & $7(14.9)$ & $3(10.7)$ & $4(21.1)$ & \\
\hline Endocervix-invasion & & & & 0.381 \\
\hline No & $42(89.4)$ & $26(92.9)$ & $16(84.2)$ & \\
\hline Yes & $5(10.6)$ & $2(7.1)$ & $3(15.8)$ & \\
\hline Pelvic_peritoneum_invasion & & & & 0.485 \\
\hline No & $36(76.6)$ & $20(71.4)$ & $16(84.2)$ & \\
\hline Yes & $11(23.4)$ & $8(28.6)$ & $3(15.8)$ & \\
\hline Endometrial FIGO stage & & & & $<.001$ \\
\hline 1 & $30(63.8)$ & $24(85.8)$ & $6(31.6)$ & \\
\hline 2 & $2(4.3)$ & $2(7.1)$ & $0(0.0)$ & \\
\hline 3 & $12(25.5)$ & $2(7.1)$ & $10(52.6)$ & \\
\hline 4 & $3(6.4)$ & $0(0.0)$ & $3(15.8)$ & \\
\hline Ovarian FIGO stage & miss $=12$ & & & 0.038 \\
\hline 1 & $19(54.2)$ & $16(57.1)$ & $3(42.9)$ & \\
\hline 2 & $8(22.9)$ & $8(28.6)$ & $0(0.0)$ & \\
\hline 3 & $7(20.0)$ & $4(14.3)$ & $3(42.9)$ & \\
\hline 4 & $1(2.9)$ & $0(0.0)$ & $1(14.2)$ & \\
\hline Endometrial histology & & & & 0.018 \\
\hline non-endometrioid & $11(23.4)$ & $3(10.7)$ & $8(42.1)$ & \\
\hline Endometrioid & $36(76.6)$ & 25 (89.3) & $11(57.9)$ & \\
\hline Ovarian histology & & & & 0.210 \\
\hline non-endometrioid & $22(46.8)$ & $11(39.3)$ & $11(57.9)$ & \\
\hline Endometrioid & $25(53.2)$ & $17(60.7)$ & $8(42.1)$ & \\
\hline Endometrial FIGO grade & miss $=8$ & & & 0.002 \\
\hline 1 & $17(43.6)$ & $16(61.5)$ & $1(7.7)$ & \\
\hline 2 & $11(28.2)$ & $6(23.1)$ & $5(38.5)$ & \\
\hline 3 & $11(28.2)$ & $4(15.4)$ & $7(53.8)$ & \\
\hline Ovarian grade & miss $=7$ & & & 0.056 \\
\hline
\end{tabular}

DP, double primary ; PALND, para-aortic lymph node dissection ; PLND, Pelvic lymph node dissection 


\begin{tabular}{|lllll|}
\hline Variables & Total $(\mathbf{N}=\mathbf{4 7})$ & $\mathrm{DP}(\mathbf{N}=\mathbf{2 8})$ & meta $(\mathbf{N}=\mathbf{1 9})$ & P-value \\
\hline 1 & $15(37.5)$ & $13(50.0)$ & $2(14.3)$ & \\
\hline 2 & $13(32.5)$ & $8(30.8)$ & $5(35.7)$ & \\
\hline 3 & $12(30.0)$ & $5(19.2)$ & $7(50.0)$ & 0.685 \\
\hline Adjuvant chemotherapy & & & \\
\hline No & $7(14.9)$ & $5(17.9)$ & $2(10.5)$ & 1.000 \\
\hline Yes & $40(85.1)$ & $23(82.1)$ & $17(89.5)$ & \\
\hline Adjuvant radiotherapy & & & $17(89.5)$ & \\
\hline No & $42(89.4)$ & $25(89.3)$ & $2(10.5)$ \\
\hline Yes & $5(10.6)$ & $3(10.7)$ & \\
\hline DP, double primary ; PALND, para-aortic lymph node dissection ; PLND, Pelvic lymph node dissection \\
\hline
\end{tabular}


Table 2

Cox-regression analysis of risk factors

\begin{tabular}{|c|c|c|c|c|c|c|}
\hline \multirow[b]{2}{*}{ Variables } & \multicolumn{3}{|c|}{ Overall survival } & \multicolumn{3}{|c|}{ Recurrence-free survival } \\
\hline & $N$ (event) & $\mathrm{HR}(95 \% \mathrm{Cl})$ & P-value & $N$ (event) & $\mathrm{HR}(95 \% \mathrm{Cl})$ & P-value \\
\hline Age & $47(4)$ & $1.05(0.93-1.18)$ & 0.428 & $47(12)$ & $1.05(0.98-1.11)$ & 0.173 \\
\hline \multicolumn{7}{|c|}{ Pelvic_LN_pathology } \\
\hline no & $41(3)$ & 1 & & $41(9)$ & 1 & \\
\hline yes & $6(1)$ & $3.57(0.36-35.05)$ & 0.275 & $6(3)$ & $3.86(0.96-15.46)$ & 0.057 \\
\hline \multicolumn{7}{|l|}{ paraaortic_LN } \\
\hline no & $42(3)$ & 1 & & $42(9)$ & 1 & \\
\hline yes & $5(1)$ & $3.80(0.39-36.90)$ & 0.250 & $5(3)$ & $4.84(1.21-19.41)$ & 0.026 \\
\hline \multicolumn{7}{|l|}{ LVS } \\
\hline no & $40(3)$ & 1 & & $40(11)$ & 1 & \\
\hline yes & $7(1)$ & $2.29(0.24-22.13)$ & 0.474 & $7(1)$ & $0.54(0.07-4.18)$ & 0.554 \\
\hline \multicolumn{7}{|l|}{ Endocervix-invasion } \\
\hline no & $42(4)$ & 1 & & $42(11)$ & 1 & \\
\hline yes & $5(0)$ & & & $5(1)$ & $0.60(0.08-4.64)$ & 0.623 \\
\hline \multicolumn{7}{|l|}{$\begin{array}{l}\text { Pelvic peritoneum } \\
\text { invasion }\end{array}$} \\
\hline no & $36(2)$ & 1 & & $36(8)$ & 1 & \\
\hline yes & $11(2)$ & $3.17(0.44-22.96)$ & 0.253 & $11(4)$ & $1.63(0.49-5.41)$ & 0.427 \\
\hline \multicolumn{7}{|l|}{ Stage_EM } \\
\hline $1+2$ & $32(2)$ & 1 & & $32(9)$ & 1 & \\
\hline $3+4$ & $15(2)$ & $2.60(0.36-18.54)$ & 0.342 & $15(3)$ & $0.71(0.19-2.63)$ & 0.610 \\
\hline \multicolumn{7}{|l|}{ Stage_OV } \\
\hline $1+2$ & $27(0)$ & 1 & & $27(3)$ & 1 & \\
\hline $3+4$ & $8(2)$ & & & $8(6)$ & $12.16(2.87-51.59)$ & 0.001 \\
\hline \multicolumn{7}{|l|}{ Histology_EM } \\
\hline non-endometrioid & $11(3)$ & 1 & & $11(7)$ & 1 & \\
\hline endometrioid & $36(1)$ & $0.09(0.01-0.84)$ & 0.035 & $36(5)$ & $0.15(0.05-0.49)$ & 0.002 \\
\hline \multicolumn{7}{|l|}{ Histology_OV } \\
\hline non-endometrioid & $22(4)$ & 1 & & $22(9)$ & 1 & \\
\hline endometrioid & $25(0)$ & & & $25(3)$ & $0.20(0.05-0.73)$ & 0.016 \\
\hline \multicolumn{7}{|l|}{ Grade_EM } \\
\hline 1 & $17(1)$ & 1 & & $17(3)$ & 1 & \\
\hline $2+3$ & $22(1)$ & $0.81(0.05-13.01)$ & 0.884 & $22(2)$ & $0.59(0.1-3.55)$ & 0.567 \\
\hline \multicolumn{7}{|l|}{ Grade_OV } \\
\hline 1 & $15(1)$ & 1 & & $15(4)$ & 1 & \\
\hline $2+3$ & $25(2)$ & $1.22(0.11-13.45)$ & 0.873 & $25(5)$ & $0.84(0.23-3.14)$ & 0.798 \\
\hline \multicolumn{7}{|l|}{ Adjuvant CTx } \\
\hline no & $7(1)$ & 1 & & $7(1)$ & 1 & \\
\hline yes & $40(3)$ & $0.47(0.05-4.54)$ & 0.516 & $40(11)$ & $1.95(0.25-15.16)$ & 0.521 \\
\hline
\end{tabular}

Cl, confidence interval; CT, chemotherapy; EM, electron microscopy; HR, hazard ratio; LN, lymph nodes; OV, ; RT, radiotherapy 


\begin{tabular}{|lllll|}
\hline \multicolumn{2}{|c|}{ Overall survival } & \multicolumn{2}{c|}{ Recurrence-free survival } \\
\hline no & $42(4)$ & 1 & $42(10)$ & 1 \\
\hline yes & $5(0)$ & $5(2)$ & $1.35(0.30-6.17)$ & 0.700 \\
\hline Cl, confidence interval; CT, chemotherapy; EM, electron microscopy; HR, hazard ratio; LN, lymph nodes; OV, ; RT, radiotherapy \\
\hline
\end{tabular}

Table 3

Clinical characteristics of recurrent patients

\begin{tabular}{|c|c|c|c|c|c|c|c|c|c|c|c|c|}
\hline Age & $\begin{array}{l}\text { Pelvic LN } \\
\text { metastasis }\end{array}$ & $\begin{array}{l}\text { paraaortic } \\
\mathrm{LN} \\
\text { metastasis }\end{array}$ & LVS & $\begin{array}{l}\text { endocervix } \\
\text { invasion }\end{array}$ & $\begin{array}{l}\text { metastasis } \\
\text { to other } \\
\text { sites }\end{array}$ & stage_EM & stage_OV & $\begin{array}{l}\text { DPC } \\
\text { or } \\
\text { MC }\end{array}$ & Histology_EM & Histology_OV & $\begin{array}{l}\text { follow } \\
\text { up } \\
\text { period }\end{array}$ & d \\
\hline 57 & yes & yes & no & no & no & IB & IIIC & DPC & clear cell & serous, Gr3 & 81 & $\mathrm{n}$ \\
\hline 56 & no & no & no & no & $\begin{array}{l}\text { yes } \\
\text { (CPLN) }\end{array}$ & IA & IV & DPC & $\begin{array}{l}\text { endometrioid, } \\
\text { Gr1 }\end{array}$ & serous & 60 & $\mathrm{n}$ \\
\hline 57 & no & no & no & no & $\begin{array}{l}\text { yes (broad } \\
\text { lig) }\end{array}$ & IA & $\| A$ & DPC & $\begin{array}{l}\text { endometrioid, } \\
\text { Gr1 }\end{array}$ & $\begin{array}{l}\text { endometrioid, } \\
\text { Gr1 }\end{array}$ & 32 & $\mathrm{n}$ \\
\hline 60 & no & no & no & yes & no & II & IA & DPC & serous & $\begin{array}{l}\text { endometrioid, } \\
\text { Gr1 }\end{array}$ & 24 & $\mathrm{n}$ \\
\hline 50 & no & no & no & no & no & IA & $\mathrm{IA}$ & DPC & $\begin{array}{l}\text { endometrioid, } \\
\text { Gr2 }\end{array}$ & seromucinous & 26 & $\mathrm{n}$ \\
\hline 60 & no & no & no & no & no & IIIA & $\mathrm{n} / \mathrm{a}$ & MC & carcinosarcoma & carcinosarcoma & 17 & $\mathrm{y}$ \\
\hline 52 & yes & yes & yes & no & $\begin{array}{l}\text { yes (CPLN, } \\
\text { broad lig) }\end{array}$ & IVB & $\mathrm{n} / \mathrm{a}$ & MC & serous, Gr3 & serous, Gr3 & 7 & $\mathrm{y}$ \\
\hline 39 & no & no & no & no & no & IIIA & $\mathrm{n} / \mathrm{a}$ & MC & serous, Gr3 & serous, Gr3 & 15 & $n$ \\
\hline 55 & no & no & no & no & no & IA & IIIC & MC & serous & serous, Gr3 & 40 & $y$ \\
\hline 60 & no & no & no & no & $\begin{array}{l}\text { yes (liver } \\
\text { capsule) }\end{array}$ & IB & IIIB & MC & $\begin{array}{l}\text { endometrioid, } \\
\mathrm{Gr} 1\end{array}$ & $\begin{array}{l}\text { endometrioid, } \\
\text { Gr1 }\end{array}$ & 61 & $\mathrm{n}$ \\
\hline 52 & no & no & no & no & $\begin{array}{l}\text { yes (broad } \\
\text { lig, } \\
\text { omentum) }\end{array}$ & IA & IIIC & MC & serous & serous, Gr3 & 22 & $y$ \\
\hline 56 & yes & yes & no & no & $\begin{array}{l}\text { yes } \\
\text { (salpinx, } \\
\text { broad lig, } \\
\text { LN meta) }\end{array}$ & IA & IIIB & MC & serous & serous, Gr3 & 59 & $\mathrm{n}$ \\
\hline
\end{tabular}

CPLN, cardio phrenic lymph nodes; DPC, double primary cancer; EM, electron microscopy; MC, metastatic cancer; LN, lymph nodes; LVS, lymphatic vessels

\section{Discussion}

The rate at which cancer is found synchronously in the ovaries and endometrium is approximately 3-10\% [19]. The Ulbright and Roth criteria proposed in 1986 help in differentiating DPC from MC. We included both DPC and MC patients in our study. However, the clinical factors and survival rate in patients in the two groups were not significantly different. Endometrioid histology of the endometrium $(P=0.002)$ and ovaries $(P=0.016)$ and para-aortic lymph node metastasis $(P=0.026)$ were the risk factors for recurrence, regardless of either DPC or MC.

Almost all SEOCs were evaluated as single primary tumors with metastasis using next-generation sequencing (NGS) in two recently published studies [18, 16, 17]. NGS is an accepted accurate diagnostic tool in various carcinomas, and it is being used increasingly for the diagnosis and treatment of endometrial and ovarian cancers. Genetic analysis using NGS may be accurate in evaluating the characteristics of cancer. However, there was no significant difference in the clinical factors or prognosis between the two groups in those studies. This led to the question of the necessity of classifying two groups and the use of NGS.

The tumor is staged as IA if it is DPC. If it is MC, it is staged as IIIA based on the endometrium or II based on the ovaries. If diagnosed as IA, no additional treatment is required. If diagnosed as IIIA or II, additional treatment is required. Using pathology in distinguishing between DPC and MC may lead to misstaging; therefore, there are potential risks of wrong management of the patients.

Whether DPC or MC is diagnosed using NGS or pathology, only using the time difference, makes it difficult to determine whether the disease occurred concurrently in both organs or it had metastasized from one organ to the other through an unknown mechanism. Making an accurate differentiation between DPC and MC remains a problem even if the pathology and NGS results are the same. A successful cancer metastasis requires a series of sequential steps such as cancer cell migration, settlement, proliferation, vascularization, etc. This is an inefficient process for cancer cells. Furthermore, even if the NGS results are different, it is impossible to rule out the possibility of either a metastases or DPC. Several reports have shown the cases wherein the genomes of the tumor origin and the metastatic site were different [20-22]. Whether or not a clear-cut difference can be established between DPC and MC using various methods, it does not affect the necessity for the adjuvant treatment. 
In this study, the clinical features of 12 patients (5 DPC and $7 \mathrm{MC}$ ) with recurrence were assessed, and these data are summarized in Table 3 . A nonendometrioid histology and a high FIGO grade were mostly observed in MC. When cancer is diagnosed in the ovary and endometrium synchronously, whether the diagnosis of DPC or MC is made using pathology or NGS, the adjuvant treatment option is determined clinically by the risk factors of each individual patient. Therefore, it would be more important to determine the risk factors and the need for adjuvant treatment rather than how the diagnosis is made.

To increase the reliability of our findings, there is a need for a large multicenter study focusing on the identification of risk factors. This can help improve the prognosis, disease-free survival, and cure rate through aggressive treatment and strong surveillance in patients with synchronous ovarian and endometrial cancer with risk factors for recurrence.

\section{Declarations}

\section{Ethics approval and consent to participate}

This retrospective study was approved by the institutional review board of our institution (IRB No. NCC2019-0272).

\section{Consent for publication}

Not applicable

\section{Availability of data and materials}

All data generated or analyzed during this study are included in this published article.

\section{Conflict of Interest}

The authors declare that they have no competing interests.

\section{Funding}

Not applicable

\section{Authors' contributions}

Conceptualization: Wonkyo Shin, Sangsoo Seo

Data analysis: Wonkyo Shin

Manuscript draft: Wonkyo Shin

Manuscript revision and review: Myongcheol Lim, Sangyoon Park, Sokbom Kang

Supervision: Sangsoo Seo

\section{Acknowledgements}

Not applicable

\section{References}

1. Siegel RL, Miller KD, Jemal A. Cancer Statistics, 2017. CA Cancer J Clin. 2017;67(1):7-30. doi:10.3322/caac.21387.

2. Lim MC, Won YJ, Ko MJ, Kim M, Shim SH, Suh DH, Kim JW. Incidence of cervical, endometrial, and ovarian cancer in Korea during 1999-2015. J Gynecol Oncol. 2019;30(1):e38. doi:10.3802/jgo.2019.30.e38.

3. Lee TS, Jung JY, Kim JW, Park NH, Song YS, Kang SB, Lee HP. Feasibility of ovarian preservation in patients with early stage endometrial carcinoma. Gynecol Oncol. 2007;104(1):52-7. doi:10.1016/j.ygyno.2006.07.003.

4. Falkenberry SS, Steinhoff MM, Gordinier M, Rappoport S, Gajewski W, Granai CO. Synchronous endometrioid tumors of the ovary and endometrium. A clinicopathologic study of 22 cases. J Reprod Med. 1996;41(10):713-8.

5. Zaino R, Whitney C, Brady MF, DeGeest K, Burger RA, Buller RE. Simultaneously detected endometrial and ovarian carcinomas-a prospective clinicopathologic study of 74 cases: a gynecologic oncology group study. Gynecol Oncol. 2001;83(2):355-62. doi:10.1006/gyno.2001.6400.

6. Soliman PT, Slomovitz BM, Broaddus RR, Sun CC, Oh JC, Eifel PJ, Gershenson DM, Lu KH. Synchronous primary cancers of the endometrium and ovary: a single institution review of 84 cases. Gynecol Oncol. 2004;94(2):456-62. doi:10.1016/j.ygyno.2004.05.006.

7. Chiang YC, Chen CA, Huang CY, Hsieh CY, Cheng WF. Synchronous primary cancers of the endometrium and ovary. Int J Gynecol Cancer. 2008;18(1):15964. doi:10.1111/j.1525-1438.2007.00975.x.

8. Chen L, Zhao Q, Lv X. Characteristics and prognosis of coexisting adnexa malignancy with endometrial cancer: a single institution review of 51 cases. Arch Gynecol Obstet. 2011;283(5):1133-7. doi:10.1007/s00404-010-1574-2. 
9. AlHilli MM, Dowdy SC, Weaver AL, St Sauver JL, Keeney GL, Mariani A, Podratz KC, Bakkum-Gamez JN. Incidence and factors associated with synchronous ovarian and endometrial cancer: a population-based case-control study. Gynecol Oncol. 2012;125(1):109-13.

doi:10.1016/j.ygyno.2011.12.444.

10. Liu Y, Li J, Jin H, Lu Y, Lu X. Clinicopathological characteristics of patients with synchronous primary endometrial and ovarian cancers: A review of 43 cases. Oncol Lett. 2013;5(1):267-70. doi:10.3892/ol.2012.943.

11. Song T, Seong SJ, Bae DS, Kim JH, Suh DH, Lee KH, Park SY, Lee TS. Prognostic factors in women with synchronous endometrial and ovarian cancers. Int J Gynecol Cancer. 2014;24(3):520-7. doi:10.1097/IGC.0000000000000073.

12. Jain V, Sekhon R, Pasricha S, Giri S, Modi KB, Shrestha E, Ram D, Rawal S. Clinicopathological Characteristics and Prognostic Factors of Synchronous Endometrial and Ovarian Cancers-A Single-Institute Review of 43 Cases. Int J Gynecol Cancer. 2017;27(5):938-46. doi:10.1097/IGC.0000000000000971.

13. Matsuo K, Machida H, Frimer M, Marcus JZ, Pejovic T, Roman LD, Wright JD. Prognosis of women with stage I endometrioid endometrial cancer and synchronous stage I endometrioid ovarian cancer. Gynecol Oncol. 2017;147(3):558-64. doi:10.1016/j.ygyno.2017.09.027.

14. Zhan X, Li L, Wu M, Lang J. The prognosis of stage IA synchronous endometrial endometrioid and ovarian carcinomas. Arch Gynecol Obstet. 2019;300(4):1045-52. doi:10.1007/s00404-019-05288-5.

15. Yoneoka Y, Yoshida H, Ishikawa M, Shimizu H, Uehara T, Murakami T, Kato T. Prognostic factors of synchronous endometrial and ovarian endometrioid carcinoma. J Gynecol Oncol. 2019;30(1):e7. doi:10.3802/jgo.2019.30.e7.

16. Anglesio MS, Wang YK, Maassen M, Horlings HM, Bashashati A, Senz J, Mackenzie R, Grewal DS, Li-Chang H, Karnezis AN, Sheffield BS, McConechy MK, Kommoss F, Taran FA, Staebler A, Shah SP, Wallwiener D, Brucker S, Gilks CB, Kommoss S, Huntsman DG. Synchronous Endometrial and Ovarian Carcinomas: Evidence of Clonality. J Natl Cancer Inst. 2016;108(6):djv428. doi:10.1093/jnci/djv428.

17. Schultheis AM, Ng CK, De Filippo MR, Piscuoglio S, Macedo GS, Gatius S, Perez Mies B, Soslow RA, Lim RS, Viale A, Huberman KH, Palacios JC, Reis-Filho JS, Matias-Guiu X, Weigelt B. Massively Parallel Sequencing-Based Clonality Analysis of Synchronous Endometrioid Endometrial and Ovarian Carcinomas. J Natl Cancer Inst. 2016;108(6):djv427. doi:10.1093/jnci/djv427.

18. Chao A, Wu RC, Jung SM, Lee YS, Chen SJ, Lu YL, Tsai CL, Lin CY, Tang YH, Chen MY, Huang HJ, Chou HH, Huang KG, Chang TC, Wang TH, Lai CH. Implication of genomic characterization in synchronous endometrial and ovarian cancers of endometrioid histology. Gynecol Oncol. 2016;143(1):60-7. doi:10.1016/j.ygyno.2016.07.114.

19. Song T, Seong SJ, Bae DS, Suh DH, Kim DY, Lee KH, Lim MC, Lee TS. Synchronous primary cancers of the endometrium and ovary in young women: a Korean Gynecologic Oncology Group Study. Gynecol Oncol. 2013;131(3):624-8. doi:10.1016/j.ygyno.2013.09.009.

20. Chambers AF, Groom AC, MacDonald IC. Dissemination and growth of cancer cells in metastatic sites. Nat Rev Cancer. 2002;2(8):563-72. doi:10.1038/nrc865.

21. Baylin SB, Jones PA. A decade of exploring the cancer epigenome - biological and translational implications. Nat Rev Cancer. 2011;11(10):726-34. doi:10.1038/nrc3130.

22. Alizadeh AA, Aranda V, Bardelli A, Blanpain C, Bock C, Borowski C, Caldas C, Califano A, Doherty M, Elsner M, Esteller M, Fitzgerald R, Korbel JO, Lichter P, Mason CE, Navin N, Pe'er D, Polyak K, Roberts CW, Siu L, Snyder A, Stower H, Swanton C, Verhaak RG, Zenklusen JC, Zuber J, Zucman-Rossi J. Toward understanding and exploiting tumor heterogeneity. Nat Med. 2015;21(8):846-53. doi:10.1038/nm.3915.

\section{Figures}

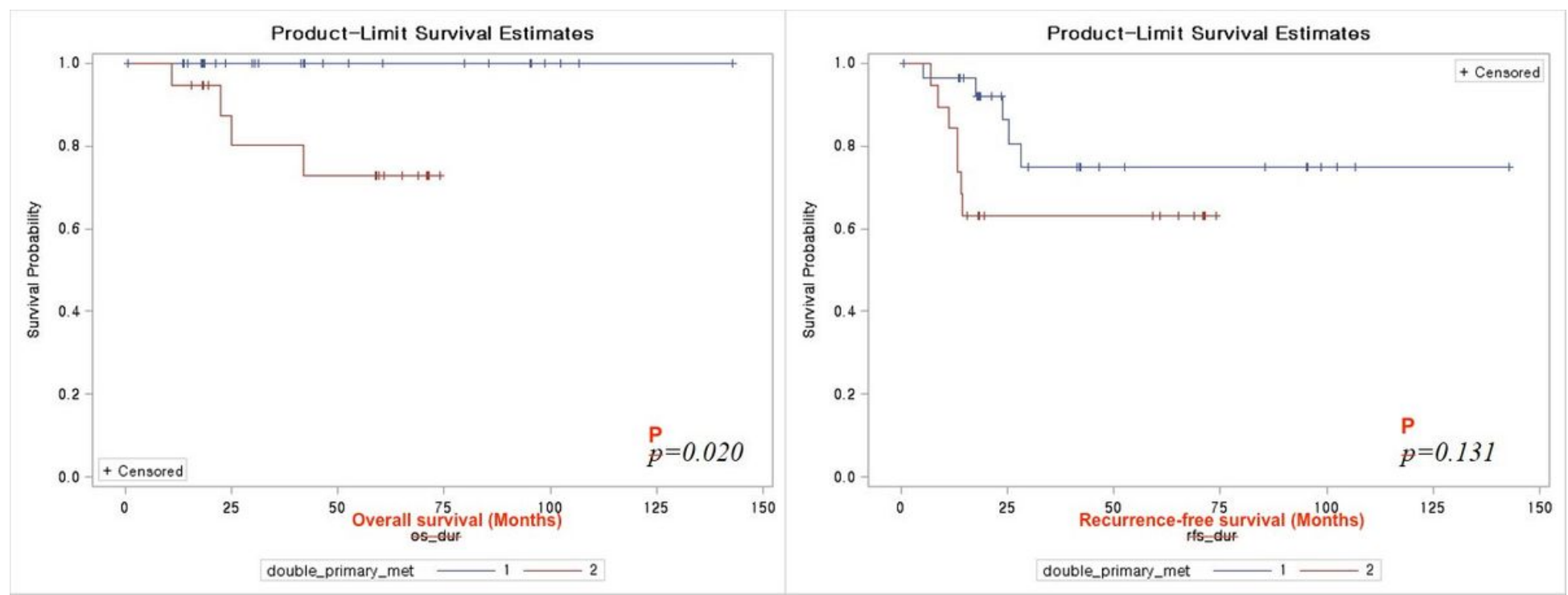

Figure 1

Kaplan-Meier overall survival and recurrence curves in DPC and MC DPC, double primary cancer; MC, metastatic cancer 

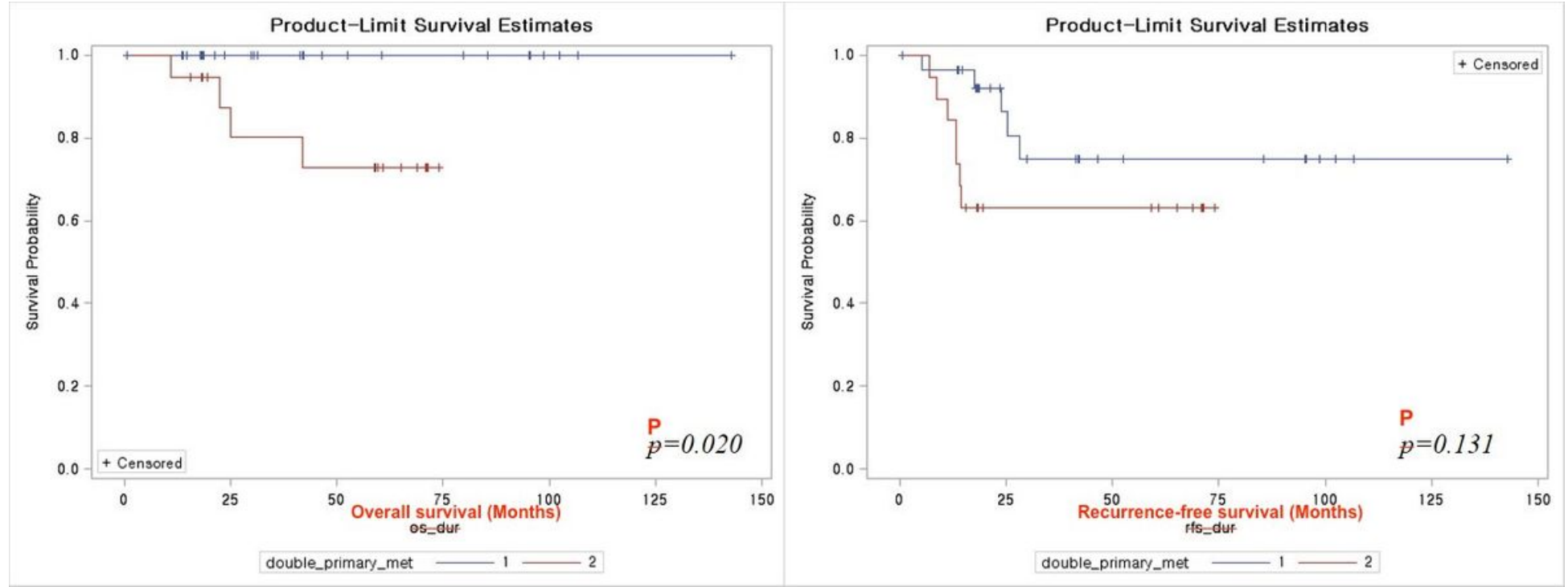

Figure 1

Kaplan-Meier overall survival and recurrence curves in DPC and MC DPC, double primary cancer; MC, metastatic cancer 